\title{
Analisis Tayangan Serial Animasi Upin Dan Ipin Dalam Perkembangan Pola Perilaku Sosial Anak Usia Dini
}

\author{
Widyaningsih Ilham, ${ }^{1}$ Andi Agustan Arifin, ${ }^{2}$ Dewi Mufidatul Ummah, ${ }^{3}$ Bujuna \\ Alhadad, $\mathbf{4}$ \\ Universitas Khairun Ternate \\ Jl. Bandara Baabullah Kampus 1 Unkhair, Kelurahan Akehuda Kota Ternate Kode Pos 97728 \\ Email: widyaningsih@gmail.com
}

\begin{abstract}
Abstrak: Penelitian ini bertujuan untuk mendeskripsikan pola perilaku sosial anak dalam animasi Upin dan Ipin. Jenis penelitian ini adalah deskripsi kualitatif karena sumber datanya diperoleh dari dialog berupa percakapan Upin, Ipin dan kawan-kawan pada episode cerita kami bagian 1 season 5, indahnya syawal bagian 1-2 season 10, ikhlas dari hati bagian 1-2 season 5 dan untuk prestasi bagian 1-3 season 12. Instrument yang digunakan untuk mengumpulkan data adalah observasi, dokumentasi dan peneliti sendiri sebagai sumber kunci. Data dianalisis secara kualitatif. Hasil penelitian menunjukan bahwa terdapat pola perilaku sosial anak pada setiap animasi Upin dan Ipin yaitu kerja sama, kemurahan hati, simpati, sikap ramah dan sikap tidak mementingkan diri sendiri. Animasi Upin dan Ipin dapat digunakan sebagai sarana untuk menumbuhkan pola perilaku sosial karena episode-episode tersebut mengandung perilaku yang baik untuk ditiru oleh anak-anak. Pengembangan pola perilaku sosial perlu didik sejak dini agar tidak menimbulkan kesulitan di kemudian hari.
\end{abstract}

Kata kunci: Animasi Upin Ipin, Perilaku Sosial, Anak

Abstract: The research aims at describing the pattern of children social behavior in Upin and Ipin cartoons. This type of research is descriptive qualitative because the data source obtained from dialogue in the form of conversations by Upin, Ipin and friends in episode Our Story part 1 season 5 , Beautiful of Syawal part 1-2 season 10, A Sincere of Heart part 1-2 season 5and Need for Achievement spart 1-3 season 12. The instruments used to collect the data are observation, documentation and the researcher herself as the key instrument. The data analyzed qualitatively. The result indicated that there children social behavior pattern found in each of the upin and ipin cartoons, those are cooperation, kind heart, care, help for others and fairness. Upin and Ipin's cartoon can be used as a means of cultivating social behavior patterns because these episodes contain good behavior to be imitated by the children. The development of social behavior patterns needs to be educated since early age so that this does not cause any difficulties in the future.

Key words: Upin Ipin Cartoon, Social Behavior, Children

\section{A. Pendahuluan}

Pendidikan anak usia dini (PAUD) adalah jenjang pendidikan sebelum pendidikan dasar yang merupakan upaya pembinaan yang ditujukan bagi anak sejak lahir sampai dengan usia 6 (enam) tahun yang dilakukan melalui pemberian rangsangan pendidikan untuk membantu pertumbuhan dan perkembangan jasmani dan rohani agar anak memiliki kesiapan dalam memasuki pendidikan lebih lanjut yang diselenggarakan pada jalur formal, non formal, dan informal. Terdapat 6 aspek perkembangan dalam pendidikan anak usia dini yaitu perkembangan moral dan agam, fisik motorik, kognitif, sosial emosional, dan bahasa yang harus di kembangkan dalam pendidikan anak usia dini (Permendikbud No 137 Tahun 2014 Tentang Standar Nasional Pendidikan anak usia dini). 
Perkembangan sosial anak usia dini berawal dari lingkungan keluarga, tempat tinggal, dan teman sebaya atau dengan animasi yang ditonton. Sebagian anak usia dini yang mengikuti kegiatan pra-sekolah mampu untuk mengembangkan perilaku sosialnya secara baik karena bisa secara langung maupun tidak langsung. Penting untuk diperhatikan dan diberikan arahan yang baik dalam meningkatkan perkembangan perilaku sosialnya karena anak-anak usia pra-sekolah cenderung meniru perilaku orang yang ada disekitarnya, karena anak usia dini memiliki kebutuhan-kebutuhan dan kemampuan-kemampuan yang berbeda-beda sesuai dengan perkembangan yang dialami sehari-hari. Oleh karena itu, dibutuhkan kondisi dan stimulasi yang sesuai dengan kebutuhan anak agar pertumbuhan dan perkembangan tercapai secara optimal sesuai dengan tingkat perkembangannya. Anak adalah penerus generasi keluarga dan bangsa, perlu mendapat perhatian yang baik sehingga potensi-potensi dirinya dapat berkembang dengan pesat, sehingga akan tumbuh menjadi manusia yang memiliki kepribadian yang tangguh dan memiliki berbagai kemampuan dan keterampilan yang bermanfaat.

Televisi merupakan media komunikasi sosial yang terbentuk dari penggabungan dua indera, pendengaran dan penglihatan, yang mempunyai inti atau tema sebuah cerita yang banyak mengungkapkan realita sosial yang terjadi di sekitar lingkungan tempat di mana televisi itu sendiri tumbuh. televisi sendiri dapat juga berarti sebuah industri, yang mengutamakan eksistensi dan ketertarikan cerita yang dapat mengajak banyak orang terlibat terutama anak-anak. Oleh karena itu ada salah satu serial animasi yang didalamnya terkandung makna dalam aspek sosial, serial animasi tersebut Upin dan Ipin.

Serial animasi upin dan Ipin adalah serial televisi animasi anak-anak yang dirilis pada 14 September 2007 di Malaysia dan disiarkan di TV9. Serial ini diproduksi oleh Les' Copaque. Awalnya film ini bertujuan untuk mendidik anak-anak agar lebih mengerti tentang Ramadan. Kini, Upin \& Ipin sudah memiliki tiga belas musim tayang. Di Indonesia, Upin \& Ipin hadir di MNCTV. Sebelum diindonesia serial animasi Upin dan Ipin pertama kali ditayangkan di Negara Malaysia yaitu Negara asal dari Upin dan Ipin sendiri. Serial ini berdurasi 100 menit per episodenya. Penayangannya setiap hari di TV9 pukul 16.30, dan di MNCTV tayang setiap hari pukul 09:00, 12:00 dan 16.00 WIB.

Nilai sebuah flim dimaksudkan bermakna semacam pesan-pesan, yang semakin harus menggarapnya akan semakin baik pula tujuan yang hendak dicapai. Dengan demikian, penonton tidak merasa dirugikan. Hampir semua film mengajari atau memberitahu kita tentang sesuatu. Namun, bila animasi lain masih menyisahkan adegan kekerasan, perkelahian dan caci maki, dalam film upin ipin semua itu tidak ada. Tayangan ini disajikan sederhana, namun komunikatif dan mendidik. Sajiannya juga mencerdaskan dan mencerahkan. Oleh karna itu orang tua pun memberikan tontonan ini kepada anakanaknya karna rasa percaya mereka terhadap perilaku sosial yang terdapat didalam animasi upin dan ipin, untuk itu animasi ini sangat berpengaruh penting untuk perkembangan perilaku positif pada anak usia dini.

Dari hasil paparan diatas Sehingga peneliti tertarik untuk melakukan penelitian dengan judul " Analisis Tayangan Serial Animasi Upin dan Ipin dalam Perkembangan Pola Perilaku Sosial Anak Usia Dini “ 


\section{B. Deskripsi Animasi Upin dan Ipin}

Sekian banyaknya hiburan serial kartun yang dipertontonkan dimedia masa terdapat salah satu yang menjadi favorit anak. Animasi lucu dan cerita yang menarik membuat kartun seperti tak pernah kehilangan penikmatnya. Sudah banyak animasi film kartun yang muncul berbagai macam karakter masih lekat dalam ingatan para penggemar animasi dari berbagai kalangan. Salah satu animasi kartun yang booming adalah Upin dan Ipin. Upin dan Ipin merupakan serial kartun anak-anak yang diproduksi oleh Les' Copaque Malaysia. Serial kartun ini pertama kali tayang pada 14 September 2007 di negara malaysia melalui siarkan TV9. Sejak penayangannya Upin dan Ipin dengan cepat mendapatkan popularitasnya cukup sukses di Negara malaysia, kartun Upin Ipin merambah ke negara-negara lain termasuk Indonesia, serial ini ditayangkan pertama kali oleh MNC TV pada tahun 2008 lalu. Serial Upin Ipin masih tetap eksis sampai sekarang dan jadi tayangan favorit anak-anak bahkan remaja.

Bukan hal aneh memang pasalnya selain lucu dan menggemaskan, Upin Ipin banyak disukai lantaran dianggap mampu memberikan pesan moral, perilaku sosial dan nilai-nilai edukatif. Cerita Upin dan Ipin yang ringan dan menggambarkan kejadian seharihari membuat serial ini digemari, selain itu aksi-aksi polos dan kocak dari dua tokoh utama dan teman-teman kampungnya juga sering sukses mengundang tawa penonton.

Melalui serial animasi Upin Ipin memiliki banyak karakter yang mendukung alur cerita, dalam setiap penggemar, pasti yang diingat adalah Upin dan Ipin, dua kakak beradik pelontos, memakai kaus singlet berwarna kuning dan biru serta memiliki mata besar. Selain itu, ada banyak teman-teman Upin, Ipin seperti Fizi, Jarjit, Ehsan, Mail, MeiMei, Susanti, Dzul dan Ijat, dibawah ini terdapat ringkasan dari tokoh-tokoh animasi upin dan ipin.

\section{Tokoh-Tokoh Dalam Animasi Upin dan Ipin}

Visiualisasi krakter tokoh-tokoh serial animasi Upin dan Ipin sebagaimana terlampir pada lampiran 1. Diuraikan sebagai berikut:

1. Upin dan Ipin

Upin dan Ipin adalah saudara kembar asal melayu yang tinggal bersama kakak perempuan dan neneknya di kampung durian runtuh. Cerita serial ini, upin lahir 3 menit lebih awal dari ipin. Sayangnya, mereka tidak merasakan kasih sayang dari orang tuanya yang sudah meninggal saat keduanya masih bayi. Untuk membedakan karakter kakak beradik yang sama-sama plontos ini adalah upin seorang kakak atau abang digambarkan memiliki satu helai rambut di kepalanya dan selalu memakai kaus kuning bertuliskan huruf $U$, sedangkan ipin diperlihatkan memakai kaus biru dengan tulisan huruf I. Ciri khas lainnya, Ipin sering melontarkan satu kalimat khas, 'betul betul betul' dan sangat menyukai ayam goreng.

2. Kak Ros

Kak Ros adalah kakak sulung Upin dan Ipin dan cucu dari opah. Kak Ros memiliki nama lengkap Jeanne Roselia Fadhullah, memiliki perawakan yang cantik tinggi dan berambut hitam sesekali kak Kos tampil mengenakan jilbab meskipun dikenal galak kepada adik-adiknya sebenarnya dia adalah seorang kakak yang 
penyayang. Kak Ros selalu mengajari adiknya agar menjadi seorang adik yang baik, berbudi mulia dan hemat. Dalam salah satu episodenya, kak Kos diceritakan jika ia pintar menggambar dan membuat animasi komik.

3. Opah

Opah memiliki nama asli mak Uda, dia adalah nenek dari Upin dan Ipin. Dari sekian banyak perilaku Upin dan Ipin mungkin opah adalah karakter yang paling bijaksana, ini terlihat saat opah menasehati Upin dan Ipin tentang keseharian atau keagamaan. opah selalu sabar mengajarkan kebaikan kepada Upin dan Ipin serta sering menegur kak Ros ketika memarah-marahi adiknya. Salah satu episodenya, opah senang sekali berkunjung ke pasar malam.

4. Jarjit

Ia adalah salah satu teman Upin dan Ipin di sekolah memiliki nama lengkap Jajit Singh, ia adalah seorang anak-anak laki-laki berketurunan india Punjabi meskipun sebaya usianya dengan teman-teman sekelasnya yang lain tetapi suaranya besar seolah-olah sudah dewasa. Jarjit juga dikenali karena kepandaian berpantun "dua tiga." adalah kata-kata yang kerap dipakai jarjit saat mulai berpantun ciri khas lain dari jarjit sering berkata 'marvelous' saat melihat atau melakukan sesuatu yang spektakuler.

5. Ehsan

Ehsan Bin Azzarudin adalah ketua kelas dari tadika mesra terlihat ia sering memakai pita di kerah baju seragamnya, namun jiwa kepemimpinanya sebagai ketua kelas berbanding terbalik dengan sifat aslinya. Ehsan sering disebut-sebut sebagai anak mama karena sangat manja dan mudah menangis teman-temannya pun sering memanggilnya 'intan payung' yang artinya anak manja ketika sedang menangis, Ia memiliki perawakan gemuk dan memakai kacamata. Ehsan juga selalu berdandan paling mewah di antara kawan kawannya setiap ada mainan baru Ehsan pasti sudah memilikinya bisa disebut ia adalah anak yang kaya dibanding teman-teman lainnya ia memiliki cita-cita sebagai juru masak yang popular.

6. Fizi

Fizi adalah perilaku Upin dan Ipin yang sangat dekat dengan Ehsan, mungkin ia bisa dibilang 'anak buah' ehsan karena saat bermain selalu membela dan membantu Ehsan. Ketika ehsan pulang Fizi pun ikut pulang Fizi memiliki rambut berponi ke depan dengan perawakan kurus, Fizi juga kerap terlihat menangis di banyak episodenya Fizi memiliki cita-cita sebagai pembersih sampah.

7. Mail

Mail adalah teman Upin dan Ipin yang paling rajin bukan cuma di sekolah mail sangat gigih mengais uang dengan berjualan apapun demi membantu ibunya. Mulai dari menjual ayam goreng, rambutan, ice cream, dan bahkan jagung bakar, ia memiliki nama panjang ismail bin mail ia dikenal sering mengatakan "dua seringgit dua seringgit" untuk menawarkan jualannya. Ia pernah berjualan ayam goreng bersama Upin dan Ipin mail memiliki perawakan lucu muka yang sayu dan rambut belah tengah khas orang zaman dulu.

8. Mei Mei

Mei Mei memiliki nama lengkap Xiao Mei-Mei ia adalah salah satu teman perempuan Upin dan Ipin ia berasal dari keturunan tionghoa dan beragama konghucu, 
meskipun beda agama namun Mei-Mei sering mengingatkan teman-temannya untuk tidak malas berpuasa. Mei-Mei juga murid paling cerdas di TK Tadika Mesra dan bercita-cita menjadi seorang guru, sebagai seorang wanita ia kerap marah-marah kepada temannya yang nakal ia suka mengatakan 'cantiknye' untuk mengungkapkan sesuatu hal yang indah.

9. Susanti

Susanti merupakan anak perempuan yang berasal dari dari Jakarta Indonesia, ia baru tinggal di malaysia dan belum terbiasa dengan obrolan anak-anak lainnya ia menggunakan bahasa indonesia untuk berkomunikasi dengan teman-temannya pertama kali muncul pada episode "berpuasa bersama kawan baru". Ia juga sangat suka bermain bulutangkis dan mengidolakan pebulutangkis legendaris asal Indonesia.

10. Dzul dan Ijat

Dzul dan Ijat merupakan teman sekelas Upin dan Ipin yang sering berdampingan Ijat ini tidak mampu berbicara dengan baik sehingga memerlukan bantuan Dzul untuk menerjemahkan kata-kata yang ia maksudkan, bisa dibilang Dzul dan Ijat adalah teman terbaik di tadika mesra. Walaupun Dzul dan Ijat jarang keluar mereka tetap teman baik dengan Upin dan Ipin, dalam suatu cerita rumah Ijat pernah kebakaran dan teman-teman sekolahnya termasuk Upin dan Ipin membantu meringankan beban Ijat.

11. Cikgu Jasmin

Cikgu Jasmin adalah wali kelas Upin, Ipin dan kawan-kawan di TK Tadika Mesra. Cikgu Jasmin seorang tenaga pengajar yang memilik pengetahuan yang luas berdedikasi dan dekat dengan murid-muridnya, dia sangat baik dan sabar mengajari murid-muridnya ketika ia akan pindah di kuala lumpur semua murid sedih dan posisi cikgu Jasmin sebagai guru kelas Tadika Mesra digantikan oleh cikgu Melati.

\section{Cikgu Melati}

Beda dengan cikgu Jasmin, cikgu Melati memiliki sifat yang lebih periang ala anak muda ia juga tak mengenakan jilbab saat mengajar ia memiliki rambut pendek, salah satu episode cikgu Melati membantu Upin Ipin dan kawan-kawan untuk mendekor taman sekolahnya.

\section{Cikgu Besar}

Cikgu Besar adalah kepala sekolah di Tadika Mesra ia memiliki tubuh yang besar dan mengenakan kerudung, ia juga sedikit galak dan sangat ditakuti oleh para murid meski dikenal galak tetapi hatinya sangat baik pada murid-muridnya.

\section{Tok Dalang}

Senin Bin Khamis atau biasa dipanggil Tok Dalang adalah tokoh masyarakat yang hadir di kampung durian runtuh sebagai tokoh masyarakat yang dituakan, Tok Dalang sering dimintai bantuan oleh Upin, Ipin dan kawan-kawannya terkadang Tok Dalang sering mengajak Upin dan Ipin pergi ke kebunnya untuk mencari durian. Kakek Dalang pun pernah memanen pohon rambutannya untuk dijual buahnya dan ia memiliki seekor ayam jantan peliharaan bernama rembo.

\section{Abang Salleh}

Salleh adalah tetangga dekat Upin dan Ipin dan dia dikenal galak namun sering tampil kemayu dan melambai. Abang Salleh atau Sally ini punya tagline yang kerap ia ucapkan yaitu "amboi" Salleh tidak memiliki pekerjaan dan kegiatan yang jelas ia 
pernah berperan sebagai tukang dekor pengantin pelayan perpustakaan keliling hingga penjaga rumah hantu.

16. Uncle Muthu

Ia merupakan satu-satunya penjual makanan di kampung durian runtuh, menu makanan dan minuman yang dihidangkan di warungnya ialah roti ikan, roti telur, nasi lemak, nasi goreng, nasi goreng pattaya, ayam goreng, mi goreng, telur mata sapi, teh tarik, es ABCD dan sebagainya. Dalam salah satu episode, yang menarik dari uncle muthu ini adalah saat mengucapkan pilihan menunya dengan cepat uncle muthu biasa mengenakan singlet dan sarung.

\section{Uncle Ah Tong}

Ah Tong adalah seorang pedagang yang berpakaian serba merah dan selalu berbicara dengan dialek china yang kental, dia dikenal suka berdagang selain itu juga bekerja sebagai pengepul keliling.

\section{Animasi Upin dan Ipin Dalam Perkembangan Pola Perilaku Sosial Anak Usia Dini}

Terdapat 5 pola perilaku sosial yang dalam masing-masing episode animmasi Upin dan Ipin yaitu (Kerja Sama, episode Cerita Kami season 5 bagian kedua berdurasi 08:24 menit - 08:50 menit dan episode Ikhlas Dari Hati season 5 bagian ketiga durasi 14:28 menit - 14:50 menit. Kemurahan Hati, episode Indahnya Syawal season 10 bagian pertama dan kedua durasi 07:30 menit - 07:53 menit, Simpati, episode Ikhlas Dari Hati season 5 bagian pertama dan kedua berdurasi 04:34 menit - 08:11 menit. Sikap Ramah, episode Untuk Prestasi season 12 bagian ketiga berdurasi 10:49 menit - 13:16 menit. Sikap Tidak Mementingkan Diri Sendiri, episode Untuk Prestasi season 12 durasi 03:18 menit - 04;02 menit dan episode Ikhlas Dari Hati dengan durasi 20:00 menit - 20:34 menit). Sebagaimana di uraiankan pola perilaku sosial di bawah ini:

1. Kerja Sama

Upin Ipin dan kawan-kawan bekerja sama dalam membuat atribut dan berlatih bersama-sama Yang dilihat pada durasi 08:24 menit-08:50 menit.

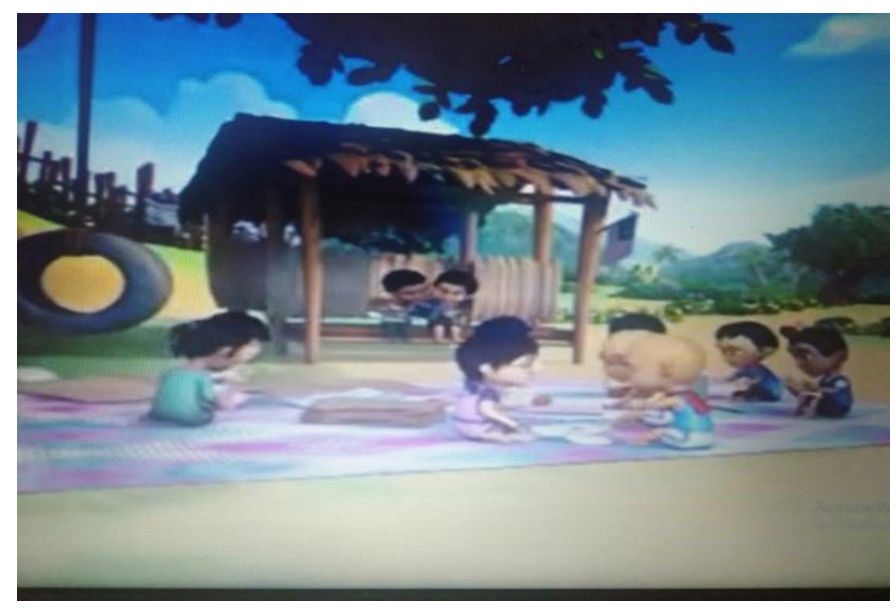

Gambar 1

Berdasarkan gambar 1 di atas terdapat kerja Sama di dalam episode (Cerita Kami) bagian atau seri kedua dan season 5 tersebut terdapat adegan Upin Ipin dan kawan-kawan pada saat mereka membuat atribut dan berlatihan bersama-sama untuk 
mempersiapan acara pentas seni peran pengembala biri-biri dan serigala yang akan ditampilkan pada saat penutupan akhir tahun pembelajaran. Dari penjelasan di atas dilihat bahwa Upin, Ipin dan kawan-kawan bekerja sama dalam melakukan tugas sekolah. Sebagaimana terdapat pada dialog di bawah ini:

Mei-mei: "tengo!" (lihat)

Upin: "mei-mei coba buat bunyi sedikit!" (mei-mei coba buat bunyi sedikit)

Mei-mei: "mmmbbbbeeeee"

Kawan-kawan: "waaaaaaaaa....tepuk tangan!"

Mei-mei: "kenapa tepuk tangan? Jangan ejek saya, saya tak suka" (kenapa tepik tangan? Jangan mengejek sayya, saya tidak suka)

Jarjid: "2 3 kambing berlari sama macam biri-biri...hahahaha" (2 3 kambing berlari sama mirip biri-biri)

Upin: "waaaahh pandainya mei-mei" (waa pintar mei-mei)

Mei-mei: "ha ia ka.mari buat sama-sama" (ha ia ka, ayo kerjakan samasama)

Upin Ipin dan kawan-kawan bekerja sama dalam mencari sumbangan lihat pada durasi 14:28 menit - 14:50 menit.

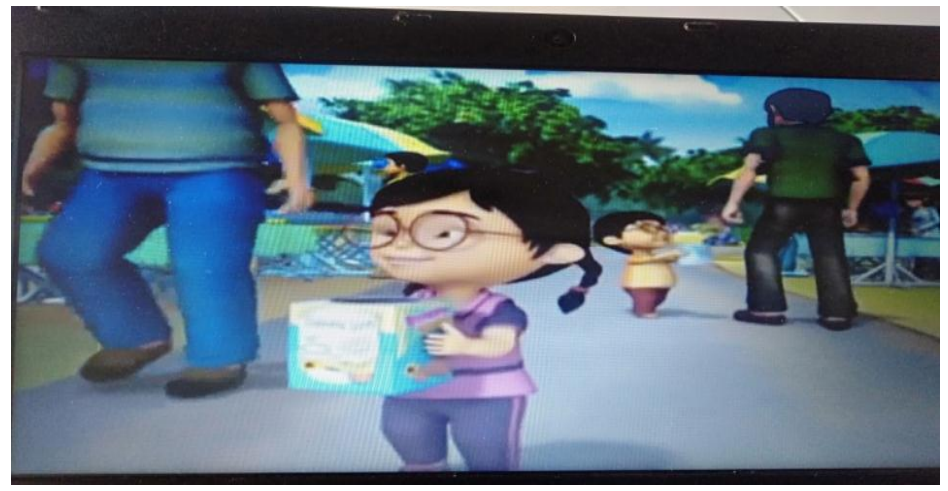

Gambar 2

Berdasarkan gambar 2 di atas kerja sama terdapat pada episode (Ikhlas dari Hati) bagian atau seri ketiga dan season 5 di dalam alur cerita tersebut Upin, Ipin dan kawan-kawan bekerja sama dalam meminta derma (sumbangan) untuk Ijat yang sedang mengalami musibah. Sebagaiman terdapat pada dialog di bawah ini:

Upin: "opah...opah...opah ada ting (kaleng) bekas ta?" (nenek...nenek...nenek ada kaleng bekak tidak)

Opah: "ting kosong ada, nah" (kaleng kosong ada, ini)

Upin dan Ipin: "terimakasih opah" (terimakasih nenek)

Opah: "na buat apa ni?" (digunakan untuk apa ini)

Ipin: "kitorang na pergi peti duit (minta sumbangan) opah, na tolong ijat" (kami akan pergi minta sumbangan nenek, mau menolong ijat)

Opah: "oooh baguslah macam tu" (ooh baguslah seperti itu) 
Berdasarkan analisis dari dua dialog di atas perilaku kerja sama yang pertama pada episode yang berjudul (Cerita Kami) Upin, Ipin dan kawan-kawan mendapatkan tugas sekolah acara penutupan akhir tahun pembelajaran disekolah, sehingga Upin, Ipin dan kawan-kawan ditugaskan untuk menampilkan satu pentas seni peran berjudul pengembala biri-biri dan serigala yang akan ditunjukan kepada orang tua murid, guru jasmin kemudian membagi peran kepada pada masing-masing anak dan menugaskan mereka berlatih bersama-sama di rumah. ketika di rumah Upin, Ipin dan kawan-kawan berkumpul untuk mengerjakan tugas bersama yaitu membuat atribut perlengkapan seperti kostum dan kemudian berlatih bersama-sama. Selanjutnya perilaku kerja sama yang kedua terdapat pada episode (Ikhlas dari Hati) dapat lihat bahwa Upin, Ipin dan kawan-kawan berinisiatif untuk membantu Ijat agar Ijat bisa bersekolah lagi dengan cara mereka meminta sumbangan pada warga.

2. Kemurahan Hati

Upin dan Ipin melihat ada anak yang sedang mencuri rambutan nya atu yang dilihat pada durasi 07:30 menit - 07:53 menit.

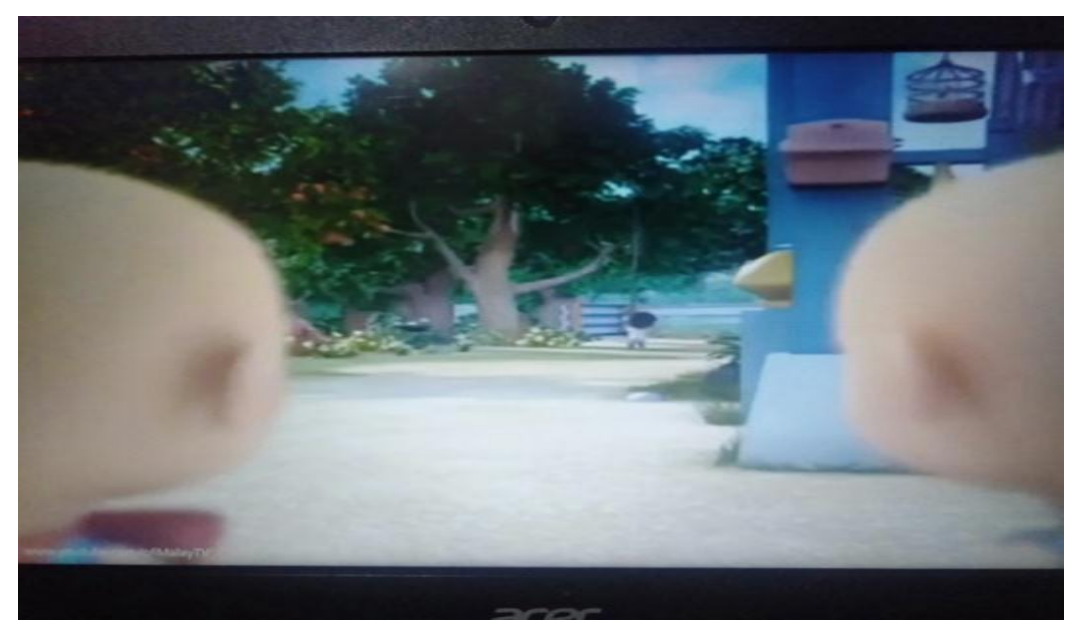

Gambar 3

Berdasarkan gambar 3 di atas terdapat kemurahan hati di dalam episode (Indahnya Syawal) bagian atau seri pertama dan kedua, season 10 dikatakan kemurahan hati terlihat pada alur cerita yaitu Upin dan Ipin yang memberikan kue atau makanan pada seorang anak yang kelaparan, Upin dan Ipin memiliki sikap murah hati karena saling berbagi pada sesama tanpa harus mengenal orang tersebut. Sebagaimana terdapat pada dialog di bawah ini:

Ka Ros:"haa kue tadi da bagi ka atu apa atu cakap? Sedap!" (haa kue tadi sudah diberikan ke kakek apa kakek bilang? Enak)

Opah: "apa ni ros? Mana atu rasa kan puasa!" (apa ini ros? Mana kakek bisa rasa kan puasa)

Upin: "sebenarnya ka kue itu kitorang tak bagi ka atu!" (sebenarnya kue itu kami tidak berikan ke kakek)

Ipin: "haa kitorang bagi seorang buda sebab dia minta dia kata dia lapar, kasiiihaan!". (ha kami bagi kue itu pada seorang anak sebab dia minta karena dia lapar, kasiihan) 
Perilaku kemurahan hati episode (Indahnya Syawal) menceritakan di bulan puasa kak Ros meminta tolong kepada Upin dan Ipin untuk membantu ka Ros membuat kue raya dan selesai membuat kue ka Ros meminta Upin dan Ipin untuk mengantarkan kue ke rumahnya atu (kakek) pada saat Upin dan Ipin sampai di rumahnnya atu keduannya melihat ada seorang anak yang mencuri buah rambutan atu, tanpa memperdulikan maksud kedatangan mereka ke rumah atu Upin dan Ipin langsung mengejar anak tersebut dengan membawa kuenya atu hingga kerumah tua ditengah hutan miliki anak tersebut, ternyata anak tersebut mencuri karena kelaparan pada saat melihat anak itu kelaparan Upin dan Ipin menjadi kasihan dengan ke murahan hati mereka akhirnya Upin dan Ipin memberikan kue milik atu kepada anak tersebut. Upin Ipin telah pulang ke rumah sampai di rumah ka Ros pun menanyakan pada Upin dan Ipin apakah kue tersebut sudah diberikan pada atu belum dan Upin dan Ipin pun mencerikan kejadiaannya bahwa mereka tidak memberikan kue tersebut pada atu melainkan kue tersebut mereka berikan pada si anak karena kasian pada si anak yang kelaparan.

3. Simpati

Upin, Ipin dan kawan-kawan menemui Ijat karena rasa kasian pada Ijat yang sedang mengalami musibah yang dilihat pada durasi 04:34 menit - 08:11 menit.

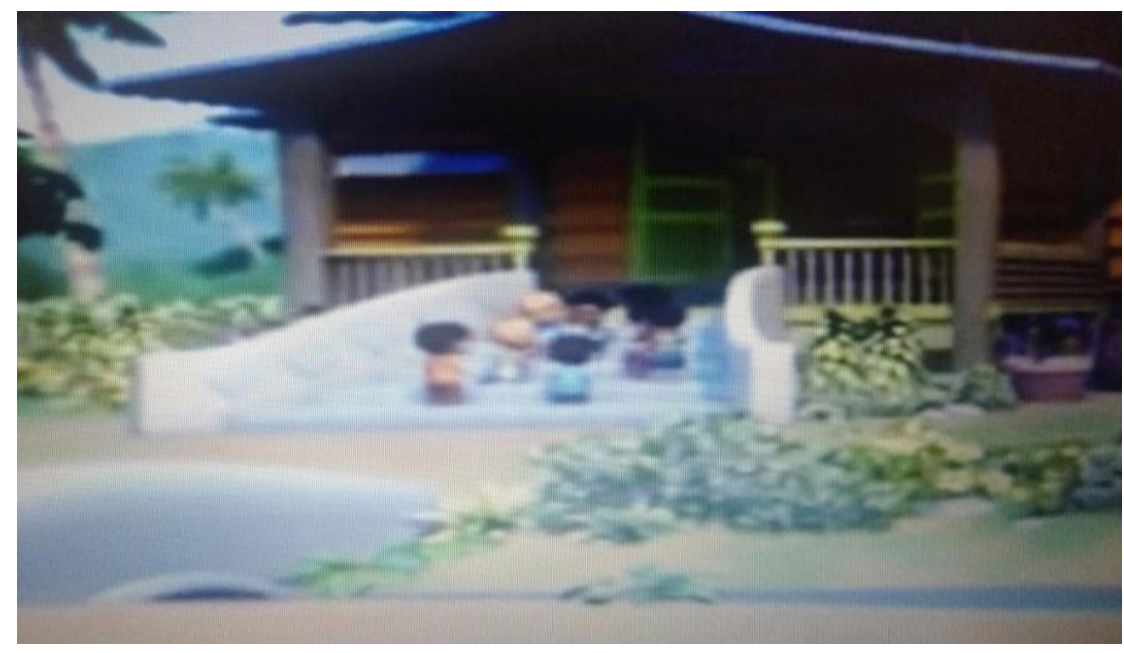

Gambar 4

Berdasarkan gambar 4 di atas pada serial animasi Upin dan Ipin episode (Ikhlas Dari Hati) bagian atau seri pertama dan kedua, season 5 yang memperlihatan sikap simpati terhadap orang lain, terlihat ketika Ijat yang bersedih karena sedang terkena musibah kebakaran rumah, pada saat itu Upin, Ipin dan kawan-kawan datang menjenguknya memberi dukungan dan berinisiatif membantu Ijat. Dikatakan simpati karena terdapat pada perilaku Upin, Ipin dan kawan-kawan yang merasa iba atau kasian pada Ijat dan berinisiatif untuk membantu Ijat. Terlihat pada dialog di bawah ini:

Zhul: "ko orang tau ta. Habis semua terbakar!" (kamu semua tau tidak. Habis semua terbakar)

Upin: "kenapa ni?" (kenapa ini)

Fizi: "ijat rumahnya terbakar!" (ijat rumahnya terbakar) 
Upin: "haaa apa! Rumah dia ka, yang terbakar semalam?" (ha apa! Rumah dia ya, yang terbakar semalam)

Ipin: "dia ta apa-apa ka?" (dia tidak apa-apa kan)

Zhul: "ta dia dengan keluarganya semua selamat, rumah ja yang terbakar!"

(tidak dia dengan keluarganya semua selamat, rumah dia saja yang terbakar)

Fizi: "habis itu mana dia sekarang?" (habis itu dimana dia sekarang)

Zhul: "dirumah paci dia!" (dirumah paman dia)

Upin: "petang nanti kitorang pergi tengok ijat na!" (sore nanti kita samasama pergi menjenguk ijat ya)

Ipin: "na...na...na!" (iya...iya...iya)

Mei-mei: "iya loh kasian ijat (iya ya kasian ijat)

Selapas itu mereka pun pergi menengok ijat.

Mei-mei: "Sabar ijat" (sabar ijat)

Ijat: "Mamasa tu" (masa itu)

Dzul: "Lepas tu ramai orang datang tolong padamkan api" (lepas itu ramai orang menolong padamkan api)

Semua: "ooooooooooooowwww"

Dzul: "eeee ko orang balik na dulu" (ee kamu semua pulang dulu)

Mei-mei: "ijat nanti kitong semua datang lagi yaaa" (ijat nanti kami semua datang lagi ya)

Ipin: "Betul...betul...betul kau jangan lah sedih sangat nanti kitong sama tolong eeehhh". (benar...benar...benar kamu jangan terlalu sedih nanti kami semua tolong kamu)

Berdasarkan dialog di atas terdapat perilaku simpati pada bagian pertama episode (Ikhlas Dari Hati) yang menceritakan tentang rumah Ijat yang terbakar, saat itu Upin, Ipin dan kawan-kawan sedang asik bermain bersama tiba-tiba Upin melihat asap hitam yang tebal bersamaan dengan itu warga yang lari berbondong-bondong lalu Upin, Ipin dan yang lain nya juga ikut berlari sambil memanggil atu (kakek) yang berada didepan mereka tapi atu menyuruh mereka jang ikut. Ke esokan paginya mereka semua bersekolah tiba-tiba Zhul yang tak lain kawan dekannya Ijat menceritakan bahwa rumah Ijat setelah pulang sekolah Upin, Ipin dan kawan-kawan bersama-sama pergi menemui Ijat dan mereka menyanyakan kejadian yang terjadi kemarin setelah di ceritakan semua teman-teman merasa iba dan mereka menguatkan Ijat dan turut perihatin terhadap Ijat dan keluargaanya

4. Sikap Ramah

Mei-Mei mendapatkan pot bunga yang baru dari upin dan ipin menggantikan pot bunga mei-mei yang pecah yang dilihat pada durasi 10:49 menit - 13:16 menit. 


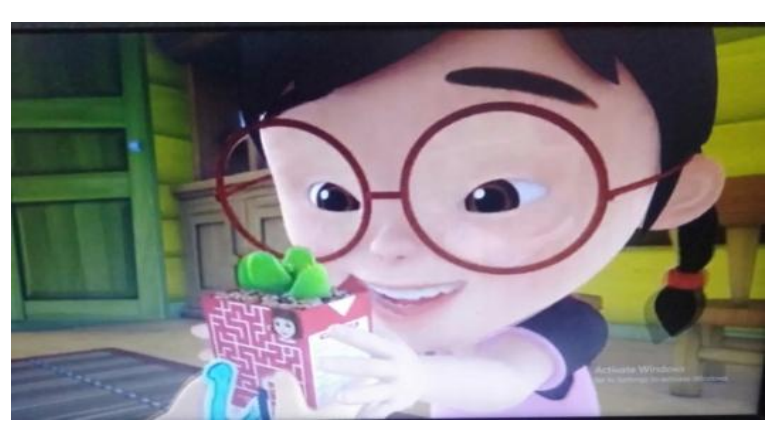

Gambar 5

Berdasarkan gambar 5 di atas dari episode (Untuk Prestasi) bagian atau seri ketiga dan season 12 di katakan sikap ramah di karenakan Upin, Ipin dan kawankawan yang membantu membuat pot bunga Mei-Mei yang baru menggantikan pot bunga Mei-Mei yang pecah karena ulah Mail yang tidak berhati-hati pada saat membawa sepeda. Sebagaimana dilihat pada dialog di bawah ini:

Upin: "mei-mei!"

Mei-mei: "hay tengok bagus bunga saya cantik kan?" (hey lihat bagus bunga saya cantik kan)

Upin: "cantik!"

Pada saat mereka saling menayapa tiba-tiba muncul mail yang sedang membawa sepeda begitu kencang dengan berteriak pada upin ipin dan meimei untuk menghindar, mereka bertiga pun berlari kebingungan pada saat berlari mei-mei tiba-tiba menendang batu dan pot bunga yang dibawah meimei pun pecah, mei-mei pun menangis dan memarahi mail pada saat mei-mei marah-marah disitu ada ipin yang sedang asik meminum susu sgm kotak upin pun melihat itu dan upin berpikir untuk membuat pot bunga yang baru buat mei-mei dari kotak bekas susu akhirnya mereka pun sama-sama pergi kerumah untuk membuat pot bunga buat mei.

Upin: "taaaada"

Ipin: "kucing yang comel untuk mei-mei yang comel" (kucing yang lucu untuk mei-mei yang lucu)

Mei-mei: "untuk saya...waaaah...saya suka saya suka...upin dan ipin sangat pandai". (untuk saya...wah saya suka saya suka upin dan ipin sangat pintar)

Dialog di atas terdapat perilaku sikap ramah pada episode (Untuk Prestasi) bercerita tentang pot bunga Mei-Mei yang pecah disebabkan oleh ulah Mail yang tidak berhati-hati dalam bersepeda karena mengejar Ehsan dan Fizi yang saat itu bermain balap sepeda bersama, Upin, Ipin dan Mei-Mei yang saat itu sedang melewati jalan itu tiba-tiba terkejut dengan teriakan Mail yang menyuruh mereka untuk menghindar lalu mereka berusaha menghindar dengan berlari hingga kaki mei-mei tersandung batu dan terjatuh yang membuat pot bunga yang dipegang mei-mei terjatuh lalu pecah, MeiMei pun menangis karena merasa bersalah ketigannya meminta maaf kemudian Upin 
dan Ipin mengajak mereka semua ke rumah Upin Ipin untuk sama-sama membuat pot bunga yang buat Mei-Mei.

5. Sikap Tidak Mementingkan Diri Sediri

Cikgu Melati membagikan susu SGM pada semua muridnya di kelas yang dilihat pada durasi 03:18 menit-04:02 menit.

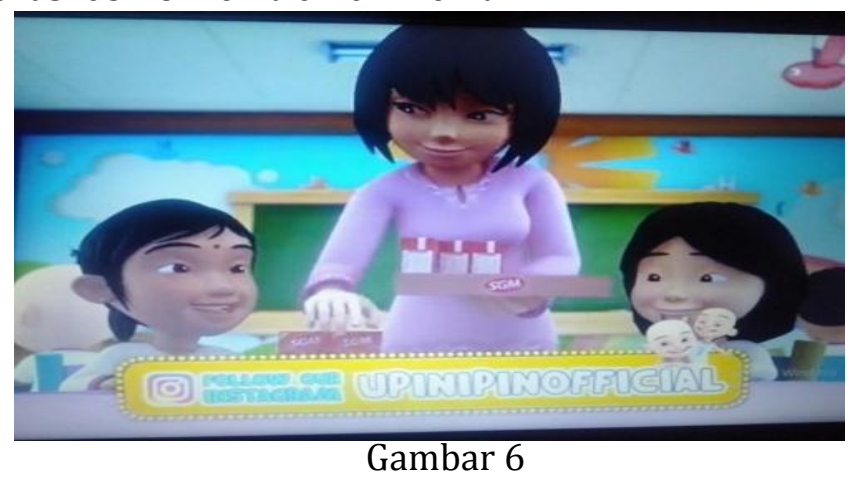

Berdasarkan gambar 6 di atas Seperti pada episode (Untuk Prestasi) bagian pertama dan season 16 dikatakan sikap tidak mementingkan diri sendiri oleh cikgu (guru) melati yang membagikan susu pada semua anak muridnya yang berada di kelas dari alur cerita tersebut bahwa cikgu melati memliki perilaku tidak pelit dalam berbagi minum dan tidak pelit dalam berbagi ilmu dengan di jelaskan oleh cikgu melatih manfaat dari meminum susu sgm untuk anak-anak hal ini menempatkan dirinya pada kebutuhan komunikasi di atas kebutuhannya sendiri dan selalu bertindak tidak hanya atas dasar kepentingannya sendiri tetapi untuk kepentingan sesama. (Achmad, 2019) Sebagaimana terlihat pada dialog di bawah ini:

Cikgu melati: "se orang satu ta" (satu orang satu ya)

Ehsan: "terimaasih cikgu" (terimakasih ibu)

Upin dan Ipin: "ini sama macam susu yang kita minum karumah" (ini semua sama dengan susu yang kita minum dirumah)

Ipin: "betul...betul...betul rasa sama sedap" (benar...benar...benar rasanya sama enak)

Susanti: "hhhmmmmm ia enak bangat" ( $h m m$ ia enak sekali)

Cikgu melati: "murit-murit kenapa kena minum susu ?" (murit-murit kenapa kita harus meminum susu)

Cikgu melati: "haa siapa na jawab? iya ehsan!" (ha siapa yang tau jawab? Iya ehsan)

Ehsan: "untukjadi besar!" (untuk bisa menjadi besar)

Cikgu metahi: "pandai ehsan, betul itu untuk kebesaran!"

(pintar ehsan, benar itu untuk menjadi besar)

Ipin: "betul...betul...betul!"

(benar...benar...benar)

Cikgu melatih: "jadi minum susu secukunya buat badan?" (jadi minum susu secukupnya buat tubuh)

Semua: "sehat!"

Cikgu melati: "dan otak?" 


\section{Semua: "cerdas!"}

Cikgu melati: "pandai!". (pintar)

Ehsan, Mei-Mei dan kawan-kawan berbagi sesuatu yang mereka miliki pada pada Ijat lihat pada durasi 20:00 menit-20:34 menit.

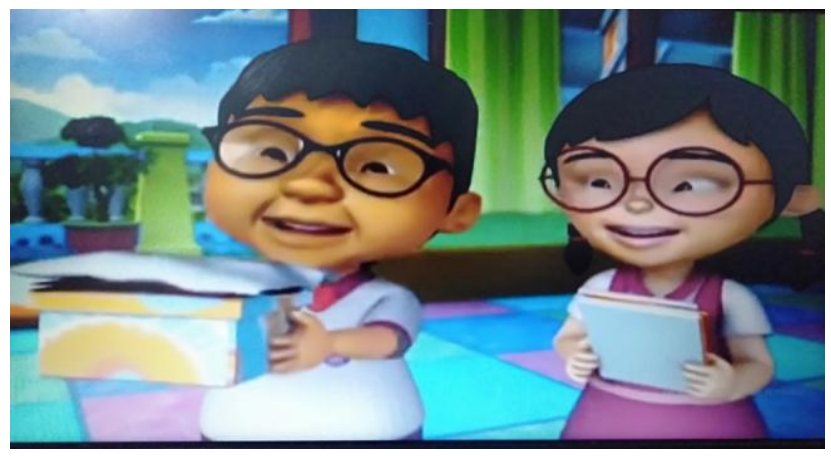

Gambar 7

Berdasarkan gambar 7 di atas sikap tidak mementingkan diri sendiri terdapat pada episode (Ikhlas Dari Hati) bagian atau seri ketiga dan season 12, didalam alur cerita tersebut yaitu Ehsan yang membagikan baju sekolah nya yang masih bagus atau masih layak di pakai pada Ijat, Mei-Mei juga yang memberikan bukunya pada Ijat dan Upin, Ipin dengan semua kawan-kawan Ijat yang memberikan sumbayangan uang kepada Ijat. Sebagaiman terdapat pada dialog di bawah ini:

Ehsan: "ijat na ini baju lamaku elok lagi ni ambil lah" (ijat ini baju lamaku masih bagus lagi ini ambil lah)

Mei-mei: "ini saya bagi (buku) ambil lah" (ini saya berikan buku ambil lah)

Upin: "ijat ni dari pada kami semua" (ijat ini dari kami semua)

Ipin: "haaa satu kampung na bagi derma (sumbangan) ni ta" (ha satu kampung ini berikan sumbangan ini)

Ijat: "terimakasih kawan-kawan" (terimakasih teman-teman)

Semua: "sama-sama"

Cikgu Jasmin: "haa macam nil ah kita berkawan, kawan dalam kesusahan kita tolong, berat sama dipikul ringan sama di jinjit"

(ha seperti ini lah kita berteman,teman yang kesusahan kita tolong, berat sama dipikul ringan sama di jinjit)

Berdasarkan analisis dari dua dialog di atas terdapat perilaku sikap tidak mementingkan diri sendiri yang pertama pada episode yang sama dengan perilaku sikap ramah. (Untuk Prestasi) menceritakan tentang cikgu (guru) melatih yang membagibagikan susu SGM kotak kepada setiap anak muridnya. Cikgu melatih pun menjelaskan tentang kepetingan meminum susu SGM. Selanjutnya sikap tidak mementingkan diri sendri pada episode (Ikhlas dari hati) bagian ketiga disini terlihat pada sikap Ehsan, MeiMei dan kawan-kawan yang mau berbagi sesuatu yang mereka miliki kepada Ijat yang sedang terkena musibah. 


\section{E. Simpulan}

Berdasarkan hasil penelitian ini dapat disimpulan bahwa dalam serial animasi Upin dan Ipin terdapat lima pola perilaku sosial pada episode Cerita Kami bagian kedua season 5, Indahnya Syawal bagian pertama dan kedua season 10, Ikhlas Dari Hati bagian pertama dan kedua season 5 dan Untuk Prestasi bagian pertama sampai ketiga season 12 . Lima pola perilaku sosial tersebut kerja sama, kemurahan hati, simpati, sikap ramah dan sikap tidak mementingkan diri sendiri. Pada kelima pola perilaku tersebut sangat berpengaruh penting untuk perkembangan perilaku sosial anak usia dini. Perkembangan perilaku sosial anak usia dini adalah bagaimana anak usia dini berinteraksi dengan teman sebaya, orang dewasa dan masyarakat luas agar dapat menyesuaikan diri dengan baik.

\section{DAFTAR PUSTAKA}

Achmad, F. (2019). Peran Pendidikan Karakter Dalam Membangun Kepribadian Pelajar di SMAN I Salem. Munaqasyah: Jurnal Pendidikan dan Pembelajaran, 2(1).

Ajeng, Dewi , dkk. 2020. Perilaku Sosial Emosional Anak Usia Dini. Jurnal Golden Age Vol 4 Juni.

Aprilia D, Kusumastuti. 2017. Peningkatan Kemampuan Kerjasama Melalui Permain Kostruktif Pada Anaka Kelompok B Di Tk ABA Plosokerep Bunder Patuk Gnungkidul. Skripsi. Universitas Negeri Yogyakarta

Basarudin. 2010. Nilai-Nilai Moral Dalam Film Serial Kartun Upin dan Ipin. Skripsi Universitas Agama Islam Negeri Purwokerto.

Brian, A \& Sri, S. 2014. Modal Sosial Dalam Komunitas Vespa Bananacity150 Di Kecamatan Gedangan Sidoarjo. Jurnal Pradikma Vol 02

Dr. Ahmad, Susanto,M.Pd. 2015. Bimbingan dan Konseling Di Taman Kanak-Kanak. Jakarta: Penerbit Pranadamedia Group

Fajar, Tri A. 2016. Perilaku Sosial Anak Usia Dini Dilingkungan Lokalisasi Guyungan. Jurnal Paud Vol I April

Farida, Mayar. 2013. Perkembangan Sosial Anak Usia Dini Sebagai Bibit Untuk Masa Depan Bangsa. Jurnal AL-Ta'Lim Vol I November

Fauzia. R. 2017. Pengaruh Tayangan Televisi Terhadap Perkembangan Perilaku Anak Pada Murid Kelas IV SD Negeri 47 Tompotikka Kecamatan Wara Kota Palopo. Skripsi Universitas Islam Alaludin Makassar.

Fauziddin. 2016. Peningkatan Kemampuan Kerja Sama Melalui Kegiatan Pada Anak Kelompok A TK Kartika Solo Kabupaten Kampar. Jurnal PG PAUD Vol 2.

Fiahliha, A. 2017. Implementasi pengembangan Nilai Agama Moral Pada Anak Usia dini Melalui Metode Keteladaan Di TK Aisyiyah I Sawahan Ngemplak Boyolali Tahun 
pelajaran 2016/2017. Skripsi Universitas Keguruan Institus Agama islam Negeri Surakarta.

Hadi, Atmoko. 2014. Strategi Pengembangan Potensi Desa Wisata Brajan Kabupaten Sleman. Jurnal Media Wisata Vol 12 November.

Nilasuwarna \& Nurlina . 2020. Perilaku Sosial Anak Yang Sedang Menonton Film Kartun Upin dan Ipin, Jurnal Paud Vol 2 Maret

Nurhabibah. 2016. Perkembangan Sosial Emosional Anak Melalui Interaksi Sosial Dengan Teman Sebaya Di Paud Nurul Hidayah Desa Lampuuk Kabupaten Aceh Besar. Skripsi Universitas Syiah Kuala Darussalam Danda Aceh

Nuryanti, Lusi. 2008. Psikologi Anak. Jakarta:Penerbit Pustaka Setia.

Rekysika. 2015. Upaya Meningkatkan Kemampuan Kerja Sama Melalui Kegiatan Kerja Kelompok Di Kelompok A TK Negeri Trukan Siwates Kaligintung Temon Kulon Progo. Skripsi Universitas Negeri Yogyakarta.

Rizki, A. 2018. Kerja Sama Dan Kekompakan Siswa Dalam Pembelajaran Fisika Di Kelas XII Mipa SMAN 3 Kota Jambi. Jurnal Penddikan Fisika Vol 3 Desember

Rohayati. 2013. Pengembangan Perilaku Sosial Anak Usia Dini. Jurnal Paud Vol 4 November.

Rosyida, N, Izzati. 2016. Hubungan Perilaku Prososial Dengan Kebermaknaan Hidup Mahasiswa Fakultas Psikologi Maulana Malik Ibrahim Malang Angkatan 2015/2016. Skripsi. Universitas Islam Negeri Maulana Malik Ibrahim Malang.

Rumini, Sri \& Siti, S. 2004. Perkembangan Anak Dan Remaja. Jakarta:Penerbit Rineka Cipta.

Santi \& Torro. 2019. Dinamika Interaksi Siswa Siswa Di UPT SMA Negeri 4 Luwu Utara Kecamatan Bone-Bone Kabupaten Luwu Utara. Jurnal Sosialisasi Vol 6 Maret.

Santrock, Jonn W. 2007. Perkembangan Anak. Jakarta:Penerbit Erlangga

Siti, M. 2018. Pengaruh Pola Asuh Orang Tua Terhadap Perkembangan Sosial Emosional Anak Usia 4-5 Tahun Didesa Bandar Abung Kecematan Abung Surakarta Kabupaten Lampung Utara. Skripsi. Universitas Islam Negeri Raden Intan.

Sugiyono. 2011. Motode Penelitian Kuantitaf Kualitati dan R\&D. Bandung: Penerbit Alfabet.

Zahwa. 2017. Kemapuan Kerjasama Anak Usia Dini Ditinjau Dari Ukuran Kelahiran Di Kelompok B RA AL-Karomah Batang. Skripsi. Universitas Negeri Semarang. 